hornbeam of the Somme and the Nieve, whose ashes contain 0.09 or 0.1 of that compound. As these two woods give about the same amount of ashes, it is evident that the oak which could only introduce 0.12 per cent. of phosphorus into the iron, would be preferable to the hornbeam, which might introduce at least 1 per cent.-Cosmos.

For the Journal of the Frauklin Institute.

On a New System of Arithmetic and Metrology, called the Tonal System. By John W. Nystrom, C. E.

Counting has in all ages been a troublesome operation to mankind; the first mode of counting was performed on the fingers, and limited first to five; then to ten, including the fingers on the two hands; and then to twenty, including the toes on the feet, which is yet the extent of counting with some tribes on our globe. The more intelligent tribes arranged their mode of counting into systems with five, ten, and some twenty as the base, and named their numbers and bases from the fingers, hands, and feet, which is probably more ancient than even languages. We can easily trace from many oriental languages that the term five means hand, ten two hands, and twenty a man, which includes fingers and toes.

The Kamtschatkans have to a very late period continued the counting on the fingers, and even yet, in the interior of the peninsula, the inhabitants count on their fingers to ten, when they clasp their hands together, then continue on their toes to twenty, when they become confused, and cry out "matuchka, matuchka," which means "mother, mother," a very common expression of excitement in the north-eastern languages.

The Hindoos seem to have been the first to adopt and introduce a uniform and complete system of calculation, with ten for the base, evidently derived from the ten fingers on the hands, which constitutes our present system of arithmetic, introduced into Europe about 900 years ago, but was probably known by the Hindoos in the time of Christ. The Roman notation was used in Europe before the introduction of the Hindoo arithmetic, and was continued in England as late as to about thirty years ago. The Hindoo arithmetic was at first unfavorably received, and in many cases met with great resistance, owing to the clumsy Roman notation which was then as firmly established in their minds as our present arithmetic is with us.

The base ten in our present system of counting was thus originated from the ten fingers on the hands by perhaps the first. tribes of the hnman race, who had no knowledge whatever of mathematics, and in consequence were wholly incapable of selecting a proper number for such an important position. Ten has no claim whatever as a base for counting; it is in reality the most unsuitable number that could reasonably be selected, of which complaints have constantly been made, and better numbers proposed.

Charles XII. of Sweden gave the numbers 8,12 , and 16 , a careful 
consideration about 150 years ago. He first selected 12, which had many advantages over 10 , being divisible by $2,3,4$, and 6 , but had only one more binary division than 10 . He then selected 16 , which is a square of 4 , and the fourth power of 2 ; this he thought was the best number for the base of arithmetic, but objected to the addition of new characters. The number 8 was then selected, and worked out to a complete system of arithmetic and metrology, with the intention of introducing it in Sweden. Charles XII. said, "It is quite ridieulous to use ten as the base for arithmetic; it can be divided only once by 2 , and then stops."

Mr. Alfred B. Taylor, of Philadelphia, proposes the number 8 as an arithmetical base, and has given a very complete and interesting historical and critical account of the decimal system, and advantages of an octonal base, published in the "Transactions of the American Pharmaceutical Association" for 1859.

The writer proposes the number 16 as a base, and has worked out a complete system of arithmetic and metrology, called the Tonal system, which was submitted to the International Decimal Association, and read at their meeting held at Bradford, Yorkshire, October 11th, 1859. A complete description of the Tonal system is published by J. B. Lippincott \& Co., Philadelphia.

Our objection to the decimal arithmetic is, that the base 10 does not admit binary divisions without fractions, which is a great inconvenience, and burdens the mind in counting. In practice we desire to divide things into the most natural fractions, as halves, quarters, eighths, sixteenths, \&c., which in our present arithmetic give long decimal tails, as $0.25,0.125,0.0625$, very unnatural and ungain expressions to use in the shop and the market. If 0.125 be shown to the people, very fow without special ellucation would understand its true meaning; and if they be told that 0.125 means one-eighth, it will be necessary to explain that the whole is divided in to 1000 parts, and that 125 parts is one-eighth of the whole. The people will then naturally reply that this is a roundabout way, and that they are not willing to divide their articles into 1000 parts in order to obtain an eighth. Among the best arithmeticians, there are very few who clearly comprehend that 125 is one-eighth of 1000 , but it is well known to be so by practice in counting.

In the Tonal system, with 16 as the base, it is easily comprehended that 0.4 is $\frac{1}{4}$, as 4 is $\frac{1}{4}$ of 16 , and that 0.2 is $\frac{1}{8}$, because 2 into 16 goes 8 times; for the natural fractions the mind is not carried further than to the base 16 .

Attempts are now being made in most parts of the civilized world, and an association has been formed for many years, for the purpose of introducing an international decimal system of metrology, but they constantly meet with the most natural and reasonable objections. Mr. Taylor says, "Decimal numeration is natural only in the sense that ignorance is natural." We know that the base 10 originated with the first people on earth, in the very rudest state of ignorance, when they even had no use for a system of metrology; but when they became 
more enlightened, accustomed to counting, and adopted systems of metrology, they found that it was easier to manage series of aliquot numbers, and therefore divided their units into parts of $8,12,16,24$, $32, \&$ c. Further, when we became more accomplished in the science of arith metic, those who had to do with numbers merely by pen and ink discovered that units conld also be divided into the absurd number 10 or 100 parts, and so the complication is dragged along and propagated by a few decimal professors, who have little or nothing to do with the practical application of numbers in the shop or the market. Cnfortunately, these professors generally occupy influential positions, and are perfect barricades against improvements in counting, which have been repeatedly suggested by practical men. 'The arguments of the decimal defenders are generally of a most feeble character; they confine themselves to mere triflings and some temporary importance, which have no bearing whatever on the utility of proposed improvements in arithmetics. See Nystrom's Tonal System, published by Lippincott \& Co., Philadelphia, in which the subject is discussed from both sides. The writer has taken great pleasure in publishing remarks from the decimal side, with the view of giving the subject a fair ventilation.

The decimal system is very convenient in the mechanical operation of calculation, when it is not necessary to impress the values on the mind, as is the case with many arithmeticians, who manage the figures and come to the result as easily as a musician who plays the handorgan; but it is not so easy for practical men and self-thinkers, who impress the values and relative positions of quantities on their mind, as they proceed in measurement and calculation. The new system about to be described has all the advantages and covers all the disadrantages of the decimal system. The reader will now be led into a new system of arithmetic, with the number 16 as the base, called the Tonal System. It is hoped he will give the subject a careful consideration, and not allow himself to be discouraged by the new names and figures, which naturally will appear strange at the first glance; reflection will soon lead to a conviction of its simplicity and importance.

Tonal Srstem.-In the Tonal System it is proposed to add six new figures to the ten arabic, thus:

$$
1,2,3,4,5,6,7,8, \jmath, 9,8, \vartheta, \mathcal{E}, \nsucc, \varphi, 10,
$$

making 16 characters to form the base. In order to form a clear conception of the nature and utility of the Tonal System, it will be well to enter into some details of calculation with examples, in connexion with which it is necessary to give names to the new figures, or rather to give new names to the 16 characters, so as to clearly distinguish it from our present system.

A new system of this kind could not well be introduced in one country alone, but the whole world at large must agree on its acceptance; it then becomes necessary in the project of the system, to select such names of the figures as to make it well suited to all languages, both

VoL. XLVI.-ThLRD SERI Es.-No. 4.-OCTODER, 1863. 
in spelling and sound; for which the following names are given, without reference to any language or thing. It is desirable to have the names clear and simple, in expressing as well compound numbers as the different units for measures. It is not necessary to employ more than one syllable for each object expressed.

Tonal Names of Single Figures and Compound Numbers.

\begin{tabular}{|c|c|c|c|c|}
\hline Noll. & 17. & Tonra. & $4 \varphi$. & Titonfy. \\
\hline An. & 18. & Tonme. & 40. & Goton. \\
\hline De. & 13. & Ionni. & 43. & Gotonti. \\
\hline Ti. & 19 . & Tonko. & 46. & Gotonby. \\
\hline Go. & 18. & Tonhu. & $4 \%$ & Gotonhu. \\
\hline Sut. & 10. & Tonvy. & 50. & Suton. \\
\hline By. & 18. & Tonla. & 80. & Meton. \\
\hline Ra. & 1\%. & Tonpo. & 80 & Huton. \\
\hline Me. & $1 \mathscr{4}$. & Tonfy. & tes. & Vytonme. \\
\hline $\mathrm{Ni}$. & 20 . & Deton. & $\mathscr{\odot}$ & Potonfy. \\
\hline Ko. & 21. & Detonan. & $\varphi \jmath$. & Fytonni. \\
\hline $\mathrm{Hu}$. & 22. & Detonde. & 100. & San. \\
\hline Vy. & 24 . & Detongo. & 101. & Sanan. \\
\hline La. & 26. & Detonby. & 102. & Sande. \\
\hline Po. & 28. & Detonme. & 106. & Sanby. \\
\hline Fy. & 28. & Detonhu. & 10\%. & Sanjōo. \\
\hline Ton. & $2 \widetilde{c}$. & Detonpo. & 110. & Santon. \\
\hline Tonan. & 30. & Titon. & 118. & Santonhu. \\
\hline Tonde. & 31. & Titonan. & 120. & Sandeton. \\
\hline Tonti. & 32. & Tidonde. & 129. & Sandetonko. \\
\hline Tongo. & 35. & Titonsu. & 130. & Santiton. \\
\hline Tonsu. & 39 . & Titonko. & 145. & Sangotonsu. \\
\hline 'Tonby. & 30 & Titonvy. & 200. & Desan. \\
\hline
\end{tabular}

284. Desan-metonfy.

700. Rasan.

$8 \mho \varphi$. Husan-vytonfy.

1000. Mill.

2000. Demill.

8\&05. Memill-husan-vytonsu.

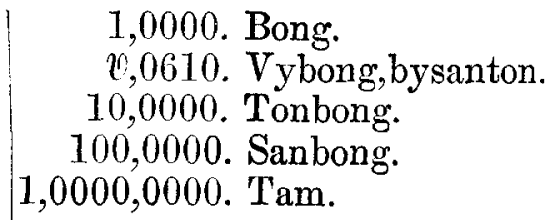

The names of the Tonal Figures are contained in the following four words, Andetigo, Subyrame, Nikohuvy, Lapofyton, which should be learned by heart. The vowel $y$ in these names should be pronounced as in the English word cylinder, $i$ as in will, $e$ as in then, $a$ as in $f a$ ther.

This arrangement of expressing numbers is clear and simple, but it requires some practice before the sound impresses the corresponding 
value on the mind, for which it is necessary to have a clear conception of the sound and value of each figure.

The number 145 is expressed in the Tonal, Sangotonsu.

The new names in the tonal system may first appear objectionable, but some reflection will soon lead to the conviction, that there is no other language so simple in expressing the same thing. Could we only attain the consent of nations to change the base of arithmetic, we would have no difficulty about the new names, for each nation could select their own tonal language; but when new names must be adopted, we may as well agree on one denomination. The Greek and Latin languages have been avoided for the very reason of their complication, neither would it be proper to adopt those names derived from the fingers, hands, toes, and feet, with which the tonal system has no connexion whatever. The Greek and Latin names may be very clear in the few who are familiar with those languages, but we have now experienced in the French system, how unsuitable they are in practice.

Decimal, one hundred and forty-five.

The Tonal system requires only 10 letters, where the decimal system employs 22 .

The object of employing different consonants to the names of the figures is to render it more difficult to alter a written number from one value to another; it will also make the expression clearer. Although the old figures in the Tonal System bears the old value (except 9) one by one, it will not be so in compound numbers, as will be seen in the following table I:

\section{Explanation of Tables.}

TABLE I shows the different notations of equal numbers in the decimal and tonal systems, where it will be seen that the new system requires a less number of figures in expressing a high number; decimal $134=86$ tonal, yet the real value is the same in both cases.

TABLE II is a further extension of Table I, useful for transferring numbers from one system to the other.

Example 1. Required how the number 31,868 will be noted by the tonal system?

$$
\text { Decimal. }\left\{\begin{aligned}
30,000=7550 \\
1,000=388 \\
800=320 \\
68=44 \\
\hline 3,1868=7050
\end{aligned}\right\} \text { Tonal. }
$$

Example 2. The year 1863 expressed by the tonal system will be $74 \varepsilon$, or it would apparently carry us back over 11 centuries.

Example 3. A lady of 35 years will be noted 23 in the tonal system. 
TABLE I.

Notation of Tonal and Decimal Numbers.

\begin{tabular}{|c|c|c|c|c|c|c|c|}
\hline Decimal. & Tonal. & Decinal. & Tonal. & Decimal. & Tonal. & Decinal. & Tonal. \\
\hline 1 & 1 & 33 & 21 & 65 & 41 & 97 & 61 \\
\hline 2 & 2 & 31 & 22 & 66 & 42 & 98 & 62 \\
\hline 3 & 3 & 95 & 23 & 67 & 43 & 99 & 63 \\
\hline 4 & 4 & 36 & 24 & 68 & 44 & 100 & 64 \\
\hline 5 & 5 & 37 & 25 & 69 & 45 & 101 & 65 \\
\hline 6 & 6 & 38 & 26 & 70 & 46 & 102 & 66 \\
\hline 7 & 7 & 39 & 27 & 71 & 47 & 103 & 67 \\
\hline 8 & 8 & 40 & 28 & 79 & 48 & 104 & 68 \\
\hline 9 & -3 & 41 & 25 & 73 & 4.5 & 105 & 63 \\
\hline 10 & 9 & 42 & 29 & 74 & 49 & 106 & 69 \\
\hline 11 & 8 & 43 & 28 & 75 & 48 & 107 & 68 \\
\hline 12 & $\mathcal{U}$ & 44 & 20 & 76 & 40 & 108 & 60 \\
\hline 13 & 8 & 45 & 28 & 77 & 48 & 109 & $6 \varepsilon$ \\
\hline 14 & ช & 46 & $2 \%$ & 78 & $4 \%$ & 110 & $6 \%$ \\
\hline 15 & $\varphi$ & 47 & 24 & 79 & $4 \varphi$ & 111 & $6 \varphi$ \\
\hline 16 & 10 & 48 & 30 & 80 & 50 & 112 & 70 \\
\hline 17 & 11 & 49 & 31 & $S I$ & 51 & 113 & 71 \\
\hline 18 & 12 & 50 & 32 & 82 & 52 & 114 & 72 \\
\hline 19 & 13 & 51 & 39 & 83 & 53 & 115 & 73 \\
\hline 20 & 14 & 52 & 34 & 84 & 54 & 116 & 74 \\
\hline 21 & 15 & 53 & 35 & 85 & 55 & 117 & 75 \\
\hline 22 & 16 & 54 & 36 & 86 & 56 & 118 & 76 \\
\hline 23 & 17 & 55 & 37 & 87 & 57 & 119 & 77 \\
\hline 24 & 18 & 56 & 38 & 88 & 58 & 120 & 78 \\
\hline 25 & $1 J$ & 57 & 33 & 89 & 53 & 121 & $7 J$ \\
\hline 26 & 19 & 58 & 39 & 90 & 50 & 122 & 79 \\
\hline 27 & 18 & 59 & 38 & 91 & 58 & 123 & 78 \\
\hline 28 & 10 & 60 & 30 & 92 & 50 & 124 & 70 \\
\hline 29 & 18 & 61 & $3 \xi$ & 93 & 58 & 125 & 78 \\
\hline 30 & 1\% & 62 & $3 \%$ & 94 & $5 \%$ & 126 & 76 \\
\hline 31 & $1 \varphi$ & 63 & $3 \varphi$ & $9 \bar{\jmath}$ & $5 \varphi$ & 127 & $7 \varphi$ \\
\hline 32 & 20 & 64 & 40 & 96 & 60 & 128 & 80 \\
\hline
\end{tabular}


On a Newo System of Arithmetic and Melrology.

TABLE I.-Continued.

Notation of Tonal and Decimal Numbers.

\begin{tabular}{|c|c|c|c|c|c|c|c|}
\hline Decimal. & Tónal. & Decimal. & Tonal. & Decimal. & Tonal. & Docimal. & Tonal. \\
\hline 129 & 81 & 161 & 91 & 193 & 01 & 225 & 81 \\
\hline 130 & 82 & 162 & 92 & 194 & $\mathfrak{O} 2$ & 226 & 62 \\
\hline 131 & 83 & 163 & 93 & 195 & 03 & 227 & 83 \\
\hline 132 & 84 & 164 & 94 & 196 & $\mathcal{V 4}$ & 228 & 64 \\
\hline 133 & 85 & 165 & 95 & 197 & 05 & 229 & 65 \\
\hline 134 & 86 & 166 & 96 & 198 & $\mathcal{V} 6$ & 230 & 66 \\
\hline 135 & 87 & 167 & 97 & 199 & $\mathfrak{v 7}$ & 231 & 87 \\
\hline 136 & 88 & 169 & 98 & 200 & 08 & 232 & 88 \\
\hline 137 & $8 \mathfrak{3}$ & 169 & $9 \jmath$ & 201 & DS & 233 & ชృ \\
\hline 138 & 89 & 170 & 99 & 202 & 09 & 234 & 89 \\
\hline 139 & $8 \%$ & 171 & 98 & 203 & 108 & 235 & 68 \\
\hline 140 & 80 & 172 & 90 & 204 & 00 & 236 & 60 \\
\hline 141 & 88 & 173 & 98 & 205 & VE & 237 & 68 \\
\hline 142 & $8 \%$ & 174 & 96 & 206 & 06 & 238 & ช6 \\
\hline 143 & $8 \varphi$ & 175 & $9 \varphi$ & 207 & $\mathscr{O P}$ & 239 & 64 \\
\hline 144 & jo & 176 & 80 & 208 & 80 & 240 & $\varphi 0$ \\
\hline 145 & 31 & 177 & 81 & 209 & 81 & 241 & $\varphi 1$ \\
\hline 146 & 32 & 178 & 82 & 210 & 82 & 242 & $\varphi 2$ \\
\hline 147 & $\jmath 3$ & 179 & 83 & 211 & 83 & 243 & $\varphi 3$ \\
\hline 148 & 34 & 180 & 84 & 212 & 84 & 244 & $\varphi 4$ \\
\hline 149 & $\$ 5$ & 181 & 85 & 213 & 85 & 245 & 45 \\
\hline 150 & J6 & 182 & 86 & 214 & 86 & 246 & 96 \\
\hline 151 & 37 & 183 & 87 & 215 & 87 & 247 & 47 \\
\hline 152 & 38 & 184 & 88 & 216 & 88 & 248 & 48 \\
\hline 153 & $J \mathcal{J}$ & 185 & 8,3 & 217 & $E S$ & 249 & $\varphi J$ \\
\hline 154 & 39 & 186 & 89 & 218 & 89 & 250 & $\varphi 9$ \\
\hline 155 & 38 & 187 & $8 \%$ & 219 & 88 & 251 & $\varphi 8$ \\
\hline 156 & 30 & 188 & 80 & 220 & 80 & 252 & $\varphi \mathcal{O}$ \\
\hline 157 & $J E$ & 189 & 88 & 221 & 88 & 253 & $\varphi \mathcal{E}$ \\
\hline 158 & ృర్ & 190 & $8 \%$ & 222 & 86 & 254 & $\Phi \sigma$ \\
\hline 159 & $J \varphi$ & 191 & 84 & 223 & $\mathcal{E P}$ & 255 & $\varphi \varphi$ \\
\hline 160 & 90 & 192 & $\mathcal{W 0}$ & 224 & 60 & 256 & 100 \\
\hline
\end{tabular}


TABLE II.

Notation of Tonal and Decimal Numbers.

\begin{tabular}{|c|c|c|c|c|c|}
\hline Decimal. & Tonal. & Decimal. & Tonal. & Decimal. & Tonal. \\
\hline 100 & 64 & 100,000 & 1,8690 & 3,584 & \\
\hline 200 & 08 & 200,000 & 3,0840 & 3,840 & \\
\hline 300 & 120 & 300,000 & $4,5 \& \widetilde{c} 0$ & 4,096 & 100 \\
\hline 400 & 130 & 400,000 & 6,1980 & 8,192 & 200 \\
\hline 500 & $1 \varphi 4$ & 500,000 & 7,9120 & 12,288 & 300 \\
\hline 600 & 258 & 600,000 & $3,27 \approx 0$ & 16,384 & 400 \\
\hline 700 & 280 & 700,000 & $9,9 \widetilde{6} 60$ & 20,480 & 500 \\
\hline 800 & 320 & 800,000 & $\mathfrak{\imath}, 3500$ & & 6000 \\
\hline 900 & 384 & 900,000 & $8,8 \% 90$ & 28,672 & 7000 \\
\hline 1,000 & 368 & $|1,000,000|$ & $\varphi, 4240$ & 32,678 & 800 \\
\hline 2,000 & 780 & $2,000,000$ & 16,8480 & 36,864 & J00 \\
\hline 3,000 & $8 \% 8$ & $3,000,000$ & $28,06 \mathrm{CO}$ & 40,960 & 900 \\
\hline 4,000 & $\varphi 90$ & $4,000,000$ & $38,0\lrcorner 00$ & 45,056 & 80 \\
\hline 5,000 & 1388 & 256 & 100 & 49,152 & v00 \\
\hline 6,000 & 1770 & 512 & 200 & 52,348 & 800 \\
\hline 7,000 & 1858 & 768 & 300 & 57,344 & 600 \\
\hline 8,000 & 2040 & 1,024 & 400 & 61,440 & $\varphi 00$ \\
\hline 9,000 & 2308 & 280 & 500 & 536 & 1,000 \\
\hline 10,000 & 2710 & 1,530 & 600 & 262,144 & 4,000 \\
\hline 20,000 & 4620 & 1,792 & 700 & 524,288 & 8,000 \\
\hline 30,000 & 7530 & 2,048 & 800 & 786,432 & 0,00 \\
\hline 40,000 & $J 840$ & 2,304 & 500 & $1,048,576$ & $\varphi, 000$ \\
\hline 50,000 & Vృృ & 2,560 & 900 & $16,777,216$ & 10,000 \\
\hline 60,000 & ช960 & 2,816 & 800 & $268,435,456$ & 100,000 \\
\hline 70,0001 &, 1170 & 3,072 & 000 & $3,489,767,296$ & 1000,0000 \\
\hline 80,0001 & , 3880 & 3,320 & 800 & $55,736,276,736$ & $1,0000,0000$ \\
\hline 90,0001 &, $5 \mathscr{f} \mathrm{J} 0$ & & & & \\
\hline
\end{tabular}


On a New System of Arilhmetic and Metrology.

TABLE III.

Vulgar Fractions, Tonals, and Decimals.

\begin{tabular}{|c|c|c|c|}
\hline Decimal. & Tonal. & Decimal. & Tonal. \\
\hline$\frac{1}{2}=0.5$ & $\frac{1}{2}=0.8$ & $\frac{11}{16}=0.6875$ & $\frac{8}{10}=0 . \%$ \\
\hline$\frac{1}{4}=0.25$ & $\frac{1}{4}=0.4$ & $\frac{13}{16}=0 \cdot 8125$ & $\frac{8}{10}=0.8$ \\
\hline$\frac{1}{8}=0 \cdot 125$ & $\frac{1}{8}=0.2$ & $\frac{15}{16}=0.9375$ & $\frac{\varphi}{10}=0 \cdot \varphi$ \\
\hline$\frac{3}{4}=0.75$ & $\frac{3}{4}=0 \cdot 0$ & $\frac{1}{32}=0.03125$ & $\frac{1}{20}=0 \cdot 08$ \\
\hline$\frac{8}{8}=0.375$ & $\frac{3}{8}=0 \cdot 6$ & $\frac{7}{24}=0.29166$. & $\frac{7}{18}=0.4999$. \\
\hline$\frac{5}{8}=0.625$ & $\frac{5}{8}=0.9$ & $\frac{5}{12}=0.4166$. & $\frac{5}{v}=0.6999 .$. \\
\hline$\frac{7}{8}=0.875$ & $\frac{7}{8}=0 \cdot 6$ & $\frac{1}{3}=0.3333$. & $\frac{1}{3}=0.5555$. \\
\hline$\frac{1}{16}=0.0625$. & $\frac{1}{10}=0 \cdot 1$ & $\frac{2}{3}=0.6666$. & $\frac{2}{3}=0.9999$. \\
\hline$\frac{3}{16}=0.1875$ & $\frac{3}{10}=0.3$ & $\frac{1}{6}=0.1666$. & $\frac{1}{6}=0.2999 .$. \\
\hline$\frac{5}{16}=0.3125$ & $\frac{5}{10}=0.5$ & $\frac{1}{64}=0.015625$ & $\frac{1}{40}=0.04$ \\
\hline$\frac{7}{16}=0.4375$ & $\frac{7}{10}=0.7$ & $\frac{25}{64}=0.380625$ & $\frac{1 s}{40}=0.64$ \\
\hline$\frac{9}{16}=0.5625$ & $\frac{5}{10}=0 \cdot 3$ & $\frac{1}{1.28}=0.0078125$ & $\frac{1}{80}=0.02$ \\
\hline
\end{tabular}


TABLE IV.

Addition and Subtraction. Tonal System.

\begin{tabular}{|c|c|c|c|c|c|c|c|c|c|c|c|c|c|c|}
\hline 1 & 2 & 3 & 4 & 5 & 0 & 7 & 8 & $\zeta$ & 9 & 8 & $v$ & $\varepsilon$ & $\widetilde{6}$ & $\mathscr{\Psi} 10$ \\
\hline 2 & 4 & 5 & 6 & 7 & $S$ & $J$ & 9 & 8 & $\mathfrak{v}$ & $\varepsilon$ & ซ & $\varphi$ & 10 & \begin{tabular}{l|l}
11 & 12
\end{tabular} \\
\hline 3 & 5 & 6 & 7 & 8 & J & 9 & 8 & $v$ & $\varepsilon$ & $\approx$ & $\varphi$ & 10 & 11 & 1213 \\
\hline 4 & 6 & 7 & 8 & 3 & 9 & 8 & 0 & $\varepsilon$ & ) & $\varphi$ & 10 & 11 & 12 & 1314 \\
\hline 5 & 7 & 8 & $\zeta$ & 9 & 8 & $\mathfrak{v}$ & $\varepsilon$ & $\widetilde{c}$ & $\varphi^{\prime}$ & 10 & 11 & 12 & 13 & 1415 \\
\hline 6 & 8 & $J$ & 9 & 8 & $v$ & $\varepsilon$ & ช & 4 & 10 & 11 & 12 & 13 & 14 & 1516 \\
\hline 7 & j & 9 & 8 & $\mathfrak{c}$ & 8 & 6 & $\mathscr{P}$ & 10 & 11 & 12 & 13 & 14 & 15 & 1617 \\
\hline$\delta$ & 9 & 8 & $\mathcal{V}$ & $\varepsilon$ & శ) & $\mathscr{4}$ & 10 & 11 . & 12 & 13 & 14 & 15 & 16 & $17 \quad 18$ \\
\hline 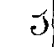 & 8 & $v$ & $\mathcal{E}$ & $\approx$ & $\varphi$ & 10 & 11 & 12 & 13 & 14 & 15 & 16 & 17 & $18 \mathrm{IJ}$ \\
\hline 9 & $\mathcal{C}$ & 8 & 6 & $\varphi$ & 10 & 11 & 12 & 13 & 14 & 15 & 16 & $|17|$ & 18 & \begin{tabular}{l|l}
$1 \circlearrowright$ & 19
\end{tabular} \\
\hline 8 & $\varepsilon$ & $\widetilde{6}$ & $\varphi$ & 10 & 11 & 12 & 13 & 14 & 15 & 16 & 17 & 18 & $1 J$ & 1918 \\
\hline$v$ & $\tilde{6}$ & $\varphi$ & 10 & 11 & 12 & 13 & 14 & 15 & 16 & 17 & 18 & $1 J$ & 19 & $1: 10$ \\
\hline $\mathcal{E}$ & $\mathscr{f}$ & 10 & 11 & 12 & 13 & 14 & 15 & 16 & 17 & 18 & $1 j$ & 19 & 18 & \begin{tabular}{l|l}
$1 \mathcal{1}$ & 18
\end{tabular} \\
\hline$\widetilde{6}$ & 10 & 11 & 12 & 13 & 14 & 15 & 16 & 17 & 18 & $1 J$ & 19 & 18 & 10 & $181 \%$ \\
\hline$\varphi$ & 11 & 12 & 13 & 14 & 15 & 16 & 17 & 18 & 15 & 19 & 18 & 10 & 18 & 1614 \\
\hline 10 & 12 & 13 & 14 & 15 & 16 & 17 & 18 & 15 & 19 & 1\% & 10 & 18 & $1 \%$ & $1 \Psi) 20$ \\
\hline
\end{tabular}

TABLE $\mathrm{V}$.

Multiplication and Division. Tonal System.

\begin{tabular}{|c|c|c|c|c|c|c|c|c|c|c|c|c|c|c|}
\hline 1 & 2 & 3 & 4 & 5 & 6 & 7 & 8 & J) & 9 & 8 & $\mathfrak{V}$ & $\varepsilon$ & \begin{tabular}{l|l|} 
है & $\varphi$
\end{tabular} & \\
\hline 2 & 4 & 6 & 8 & 9 & $\mathscr{V}$ & c) & 10 & 12 & 14 & 16 & & & 1016 & \\
\hline 0 & 6 & $\jmath$ & $v$ & $\varphi$ & 12 & 15 & 18 & 18 & 16 & 21 & & & & \\
\hline 4 & 8 & $v$ & 10 & 14 & 18 & $1 v$ & 20 & 24 & 28 & $2 v$ & 31 & 4 & & \\
\hline 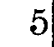 & 9 & $\varphi$ & 14 & 13 & 1 a & 29 & 28 & $2 \mathcal{E}$ & 32 & 37 & 30 & 41 & & \\
\hline 6 & $\mathfrak{V}$ & 12 & 18 & $1 \%$ & 24 & 29 & 30 & 36 & 30 & 42 & & $4 \mathscr{6}$ & & \\
\hline 7 & 8 & 15 & $1 \mathcal{C}$ & 23 & 29 & 31 & 38 & $3 \varphi$ & 46 & 48 & 54 & $5 \&$ & & \\
\hline 8 & 10 & 18 & 20 & 28 & 30 & 38 & 40 & 48 & 50 & 58 & 0 & 68 & & \\
\hline J & 12 & 18. & 24 & $2 \varepsilon$ & 36 & $3 \oplus$ & 48 & 51 & 59 & 63 & 62 & 75 & 7687 & \\
\hline 9 & 14 & 16 & 28 & 32 & 30 & 46 & 50 & 59 & 64 & 66 & & 82 & $80-36$ & \\
\hline 8 & 16 & 21 & 20 & 37 & 42 & 48 & 08 & 63 & 68 & 75 & & 84 & & \\
\hline $\mathfrak{V}$ & 18 & 2 & 30 & $3 \mathcal{V}$ & 48 & 54 & 60 & $6 v$ & 78 & 84 & & $3 v$ & & \\
\hline & 19 & 27 & 34 & 41 & $4 \approx$ & 58 & 68 & 75 & 82 & 84 & & 99 & & \\
\hline ש & 10 & 29 & 38 & 46 & 54 & 62 & 70 & $7 z$ & 80 & 59 & & 86 & $\mathfrak{C}_{4} / \mathcal{E} 2$ & \\
\hline$\varphi$ & 18 & 23 & $3 v$ & 48 & 59 & 65 & 78 & 87 & 56 & 95 & & ve & 82 & \\
\hline 10 & 20 & 30 & 40 & 50 & 60 & 70 & 80 & Ј0 & 90 & & & 80 & $\widetilde{\sigma} 0|\varphi 0| 1$ & \\
\hline
\end{tabular}

TABLE III is an excellent illustration of the utility of the tonal system. It contains the ordinary fractions used in the shop and the market. It will be seen that the vulgar fractions in daily use, require four to seven decimals, where the tonal system require only one or two figures. It must be admitted that it is more natural to divide 
things into halves, quarters, eighths or sixteenths, than into fifths or tenths, and when the natural fractions are expressed by decimals, they become too complicated for the ordinary uneducated mind, as ${ }_{16}^{3}$ is equal to $0 \cdot 1875$, which cannot be conceived by the very best arithmeticians, but they know by practice in calculation that it is so. In the tonal system it is very easy to conceive that $\frac{3}{16}$ is equal to 0.3 .

TABLE IV is for addition and subtraction, arranged in the ordinary way, that where the vertical and horizontal columns cross one another is the sum of the index numbers.

Example $4.3+5=8,5+9=\mathscr{P}$, and $8+\widetilde{\sigma}=15$.

For subtraction, find the greatest number in the column in which the smaller number is the index, and the index of the cross column is the difference, as $17-v=\%$.

ADDITION.

Ex. 5. $\left\{\begin{array}{lr}\text { To } & 36896 \\ \text { Add } & 10378 \\ \text { Same } \overline{47526}\end{array}\right.$

$$
\left.\begin{array}{r}
\mho+8=16 \\
9+7=11 \\
8+\jmath=14 \ldots \\
6+0=6 \ldots \\
3+1=4 \ldots \\
47526
\end{array}\right\}
$$

Ex. 6. $\left\{\begin{array}{r}8943 \\ 45 \% 8 \\ 308 \\ \hline 8360\end{array}\right.$

$$
\begin{aligned}
& 5+8+8=10 \\
& \varphi+\varepsilon+0=18 \\
& 9+5+3=12 \\
& 4+8=v
\end{aligned}
$$

Ex. 7. $\left\{\begin{array}{r}3819 \cdot \varepsilon \varphi \\ 680 \cdot 01 \\ 43.34 \\ 0.03 \\ 0.49 \\ \hline 3 \varphi v 8 \cdot 61\end{array}\right.$

SUBTRACTION.

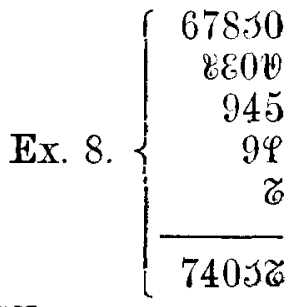

Ex. J. $\left\{\begin{array}{l}\text { From } 38694 \\ \text { Subt. } \frac{48 J 3}{\text { Diff. }} 34310\end{array}\right\}$

Ex. 9. $\left\{\begin{array}{r}+810468 \\ -\frac{4250 \varphi}{708880}\end{array}\right.$

Ex. \&. $\left\{\begin{array}{l}+89880 \cdot 01 \varphi \\ -\frac{600 \varphi \cdot 301}{70800 \cdot 816}\end{array}\right.$ 
In all arithmetical operations, the tonal fractions work precisely the same as decimal fractions.

TABLE $\mathrm{V}$ is an ordinary arranged multiplication table. MULTIPLICATION.

Ex. ข. $\left\{\begin{array}{r}38986 \\ \frac{6}{154044}\end{array}\right.$

Ex. \&. $\left\{\begin{array}{r}80549 \\ 72 \\ 101344 \\ 384586 \\ \hline 3547151\end{array}\right.$
$6 \times 6=24$

$6 \times 8=42$.

$6 \times 9=30$

$6 \times 8=30 \ldots$

$6 \times 3=12 \ldots$

154044

$38 \& 606 \cdot 4 \varphi$

$0 \cdot 00684$

ส2981590

105403278 .

154742589

$1718 \cdot 6211950$

DIVISION.

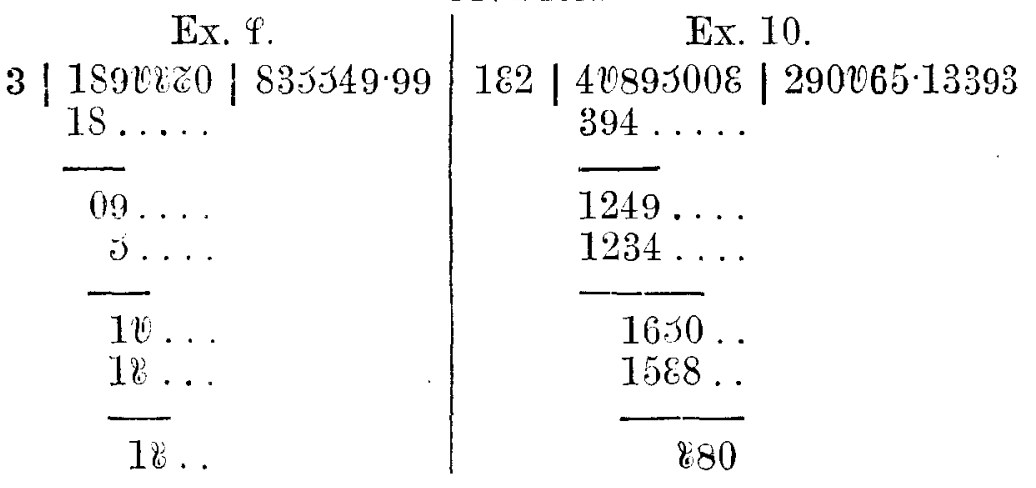

Table of Tonal Logarithms.

\begin{tabular}{|c|c|c|c|}
\hline Number. & Logarithm. & Number. & Logarithm. \\
\hline 1 & $0 \cdot 0$ & $J$ & $0 \cdot 08$ \\
\hline 2 & $0 \cdot 4$ & 9 & $0 \cdot \varepsilon 4$ \\
\hline 3 & $0 \cdot 66$ & $\mathscr{B}$ & $0 \cdot \varepsilon \&$ \\
\hline 4 & 0.8 & 0 & $0 \cdot 66$ \\
\hline 5 & $0 \cdot 54$ & $\varepsilon$ & 0.68 \\
\hline 6 & 0.96 & б & $0 \cdot \varphi 4$ \\
\hline 7 & 0.84 & $\varphi$ & 0.48 \\
\hline 8 & $0 \cdot 0$ & 10 & $1 \cdot 00$ \\
\hline
\end{tabular}


This table of tonal logarithms is a good illustration of the simplicity of the system. In logarithms for single figures, the montissa contains only one or two tonals, where the decimal system has a tail of an endless number of decimals.

The Tonal multiplication table extends two and a half-times further than the decimal one, still, the latter is about that much more difficult to learn than the former, owing to the natural location of aliquot numbers in the tonal base; for instance, 6 times 8 is 48 decimal, which must be learnt by heart, but in the tonal system we know that 8 is half the base, and half of 6 is 3 , or three times the base, $6 \times 8=30$.

Decimal $12 \times 12=144$, which is known by practice in calculation or by regular multiplication, but in the tonal system we know that twelve, which is denoted by $v$, is 3 of the base, and $\frac{3}{4}$ of twelve is nine, denoted by s, or $v \times v=$ sil.

It is surprising to know to what extent and readiness mental calculation can be performed by the tonal system; for ordinary purposes in the shop and the market, slate and pencil would rarely be necessary. The writer often porforms calculations in the tonal system, and transfers the result to decimal arithmetic.

The apparent difficulty of learning and introducing the tonal system, would soon be removed when once started, for the people would jick it up sooner than the accomplished arithmeticians, on account of it being natural to the mind, which will be further explained in the tonal metrology.

When we attempt to introduce the unnatural decimal system, why should we hesitate to bring forward that which is natural to the mind?

(To be continued on Tontal Metrologs.)

\section{The Golden Parallels.}

From the Journal of the Society of Arts, No. 560 .

In the late number of the Edinburgh Review, there is a notice of several publications on the subject of gold fields and gold miners. A mass of facts is collected relative to the Australian, California, and Columbian gold diggings, and several important conclusions are arrived at. In the first place, we are reminded that the great gold fields already discovered are all included within two regions. The gold fields of New South Wales and Victoria extend without any interruption along the slopes of the great mountain range which separates the eastern seaboard of Australia from the interior of the continent, and the gold fields of California and British Columbia occur without interruption along the western slopes of the Rocky Mountains. Thus, there are presented two great gold-bearing regions, extending along two widely distant elevations, and probably "owing their auriferous character to some influence connected with the upheaval." The possibility of establishing a connexion between these two gold-bearing regions will be understood after a little consideration of their charac- 